\title{
Electrolytic Characteristics of Fluoroethylene Carbonate for Electric Double-Layer Capacitors at High Concentrations of Electrolyte

\author{
Noritoshi NAMBU, ${ }^{a}, *$ Ryosuke TAKAHASHI, ${ }^{a}$ Masahiro TAKEHARA, ${ }^{b}$ \\ Makoto UE, ${ }^{b}$ and Yukio SASAKI ${ }^{a}$
}

\author{
a Department of Life Science and Sustainable Chemistry (Former name: Department of Nanochemistry), \\ Faculty of Engineering, Tokyo Polytechnic University, 1583 Iiyama, Atsugi, Kanagawa 243-0297, Japan \\ b Mitsubishi Chemical Group Science and Technology Research Center, Inc., \\ 8-3-1 Chuo, Ami, Inashiki, Ibaraki 300-0332, Japan
}

* Corresponding author: nanbu@chem.t-kougei.ac.jp

\begin{abstract}
The use of partially fluorinated compounds as alternative solvents can increase the solubility of electrolytes and improve the performance of electric double-layer capacitors (EDLCs). The solubility of triethylmethylammonium tetrafluoroborate $\left(\mathrm{TEMABF}_{4}\right)$ in fluoroethylene carbonate (FEC) was $3.0 \mathrm{M}\left(\mathrm{M}=\mathrm{mol} \mathrm{dm}^{-3}\right.$ ) or more at $25^{\circ} \mathrm{C}$. The molar concentration of FEC in 2.5 $\mathrm{M} \mathrm{TEMABF}_{4}$ solution was higher than that of propylene carbonate (PC) in $2.0 \mathrm{M}$ $\mathrm{TEMABF}_{4}$ solution. The kinematic viscosity and ionic conductivity of $2.0 \mathrm{M} \mathrm{TEMABF} 4$ solution in FEC were slightly lower than those of the counterpart in $\mathrm{PC}$ at room temperature. The use of $\mathrm{TEMABF}_{4}$ at the high concentrations in FEC slightly increased the gravimetric capacitance of coin cells.
\end{abstract}

(c) The Electrochemical Society of Japan, All rights reserved.

Keywords : Concentrated Solution, Fluoroethylene Carbonate, Donor Number, Capacitance

\section{Introduction}

Electric double-layer capacitors (EDLC) electrostatically store the electrical energy achieved by separation of charge in an electrical double layer present in the interphase between the surface of a conductor electrode and an electrolytic solution. ${ }^{1}$ Propylene carbonate (PC or 4-methyl-1,3-dioxolan-2-one) is commonly used as the single solvent for the EDLCs. Triethylmethylammonium tetrafluoroborate $\left(\mathrm{TEMABF}_{4}\right)$ and tetraethylammonium tetrafluoroborate $\left(\mathrm{TEABF}_{4}\right)$ are commonly used as the single electrolytes for the EDLCs. We previously reported that the use of fluoroethylene carbonate (FEC or 4-fluoro-1,3-dioxolan-2-one) as an alternative single solvent increased the capacitances of EDLCs. ${ }^{2}$ We used $\mathrm{TEABF}_{4}$ as the electrolyte, and the concentration of $\mathrm{TEABF}_{4}$ was set to $1.0 \mathrm{M}\left(\mathrm{M}=\mathrm{mol} \mathrm{dm}^{-3}\right)$ at $25^{\circ} \mathrm{C}$. The solubility of $\mathrm{TEABF}_{4}$ in $\mathrm{PC}$ is about $1.1 \mathrm{M}$ at $25^{\circ} \mathrm{C},{ }^{3,4}$ whereas that of $\mathrm{TEMABF}_{4}$ is $2.2-$ $2.3 \mathrm{M}$ at $25^{\circ} \mathrm{C} .{ }^{3,4}$ Both the concentration of charge carriers and the availability of pores can be improved at moderately high concentrations of the electrolytes. The relative permittivity of FEC (about 107 at $\left.25^{\circ} \mathrm{C}\right)^{5}$ is considerably higher than that of PC (64.92 at $\left.25^{\circ} \mathrm{C}\right) .^{6}$ Therefore, the solubility of the electrolytes in FEC can be also higher than that in PC. FEC is known as an excellent additive or co-solvent for lithium-ion secondary batteries. ${ }^{7-9}$ FEC suppresses the decomposition of the electrolytic solution and increases the efficiency of the charge and discharge of the lithium-ion cells.

There are two basic strategies to realize highly concentrated and conductive solutions containing electrolytes: designs for electrolytes and solvents. We focus the present paper on the design for a single solvent, and we describe the electrolytic characteristics of FEC for EDLCs at high concentrations of $\mathrm{TEMABF}_{4}(2.0,2.5$, and $3.0 \mathrm{M})$. The solubility of $\mathrm{TEMABF}_{4}$ in $\mathrm{FEC}$ was $3.0 \mathrm{M}$ or more at $25^{\circ} \mathrm{C}$. The molar concentrations of the solvents and the viscosities, kinematic viscosities, and ionic conductivities of the electrolytic solutions are shown as a function of temperature. Furthermore, we have evaluated the performance of EDLCs.

\section{Experimental}

The apparatus and techniques for measurement are essentially the same as those previously reported. ${ }^{2,10-13}$ Donor numbers $(D N)$ and acceptor numbers $(A N)$ were estimated from ${ }^{29} \mathrm{Si}$ NMR chemical shifts of triphenylsilanol and ${ }^{13} \mathrm{C}$ NMR chemical shifts of acetone, respectively. ${ }^{14}$

We evaluated the charge and discharge characteristics of EDLCs. Activated carbon electrodes contained 83.0 mass $\%$ activated charcoal (specific surface area: about $1700 \mathrm{~m}^{2} \mathrm{~g}^{-1}$, pore volume: about $0.75 \mathrm{~mL} \mathrm{~g}^{-1}$ ), 10.7 mass\% conductor, 4.0 mass\% dispersant, and 2.3 mass $\%$ binder. The performance of 2025-type coin cells (can size: $20 \mathrm{~mm}$ in diameter and $2.5 \mathrm{~mm}$ in thickness, stainless steel body) was investigated with a charge/discharge unit (ASKA, Model ACD-M01-05N). A separator (Celgard Inc., \#3501) was sandwiched between two identical-size activated carbon electrodes in the coin cells. The coin cells were charged in a CC$\mathrm{CV}$ (constant current $\left(-0.5 \mathrm{~mA}\left(-60 \mathrm{~mA} \mathrm{~g}^{-1}\right)\right)$-constant voltage $(2.0 \mathrm{~V}))$ regime for $60 \mathrm{~min}$. Afterward, they were discharged at $+0.5 \mathrm{~mA}$.

FEC was dehydrated with purified molecular sieves $4 \mathrm{~A}$ before use. $\mathrm{PC}$ as a reference standard for a solvent and $\mathrm{TEMABF}_{4}$ as an electrolyte were used as received (LBG and CPG of Kishida Chemical Co., Ltd.). The preparation of FEC and PC solutions and the fabrication of the EDLCs were carried out in an argon-filled glove box system made by VAC.

\section{Results and Discussion}

\subsection{Mechanical properties of electrolytic solutions}

Although FEC (fp $17.3^{\circ} \mathrm{C}$ ) ${ }^{9}$ is a solid below room temperature, the high molal depression of their freezing points makes it possible to prepare room-temperature electrolytic solutions. Figure 1(a) shows the temperature $(\theta)$ dependence of molar concentrations $\left(c_{\text {solvent }}(\theta)\right)$ of FEC and PC in the electrolytic solutions. We used $\mathrm{TEMABF}_{4}$ as a quaternary ammonium compound (QA) for EDLCs. 

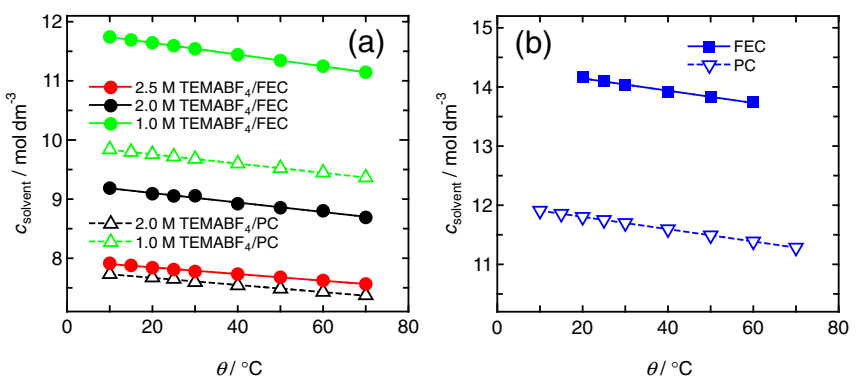

Figure 1. (Color online) (a) Molar concentrations ( $\left.c_{\text {solvent }}\right)$ of FEC and $\mathrm{PC}$ as solvents in electrolytic solutions as a function of temperature $(\theta)$ from 10 to $70^{\circ} \mathrm{C}$. The molar concentrations of the solvents were calculated from Eq. (1). The molar concentrations of $\mathrm{TEMABF}_{4}$ in $\mathrm{FEC}$ were set to $1.0,2.0$, and $2.5 \mathrm{M}$ at $25^{\circ} \mathrm{C}$; and those of $\mathrm{TEMABF}_{4}$ in $\mathrm{PC}$ were set to 1.0 and $2.0 \mathrm{M}$ at $25^{\circ} \mathrm{C}$. Included in Fig. 1(b) for comparison are data for FEC and PC solvents.

The molar concentrations of the solvents were calculated from the following equation:

$$
c_{\text {solvent }}(\theta)=\frac{d(\theta)}{d\left(25^{\circ} \mathrm{C}\right)} \cdot \frac{d\left(25^{\circ} \mathrm{C}\right)-M_{\mathrm{QA}} c_{\mathrm{QA}}\left(25^{\circ} \mathrm{C}\right)}{M_{\text {solvent }}}
$$

Here the mass density of the electrolytic solution at $\theta$ is expressed by $d(\theta) . M_{\text {solvent }}$ stands for the molar mass of the solvent. $M_{\mathrm{QA}}$ represents the molar mass of $\mathrm{TEMABF}_{4}$, and $c_{\mathrm{QA}}\left(25^{\circ} \mathrm{C}\right)$ denotes the molar concentration of $\mathrm{TEMABF}_{4}$ at $25^{\circ} \mathrm{C}$. Included in Fig. 1(b) for comparison are data for FEC and PC solvents $\left(c_{\mathrm{QA}}=0\right)$.

The use of FEC as an alternative single solvent increased the molar concentration of the solvent in the electrolytic solution as compared to the use of PC. Furthermore, as the molar concentration of $\mathrm{TEMABF}_{4}$ increased, the molar concentrations of the

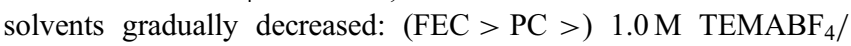
$\mathrm{FEC}>1.0 \mathrm{M} \quad \mathrm{TEMABF}_{4} / \mathrm{PC}>2.0 \mathrm{M} \quad \mathrm{TEMABF}_{4} / \mathrm{FEC}>2.5 \mathrm{M}$ $\mathrm{TEMABF}_{4} / \mathrm{FEC}>2.0 \mathrm{M} \mathrm{TEMABF}_{4} / \mathrm{PC}$. It should be noted that the molar concentration of $\mathrm{FEC}$ in $2.5 \mathrm{M} \mathrm{TEMABF} 4$ solution was higher than that of $\mathrm{PC}$ in $2.0 \mathrm{M} \mathrm{TEMABF} 4$ solution. The molar concentration of the solvent reflects both the strength of molecular attraction and the reverse of the molar volume. The synergistic effect on the molar concentration of FEC can result from the small molar volume of FEC and the attraction of FEC molecules. The attraction of FEC molecules can be based on nonconventional weak intermolecular hydrogen bonding $(\mathrm{CF}-\mathrm{H} \cdots \mathrm{O}=\mathrm{C} \text { or } \mathrm{C}-\mathrm{H} \cdots \mathrm{F}-\mathrm{C})^{15}$ as well as conventional dipole-dipole interactions. The weak hydrogenbonding system does not exchange its proton and therefore it is no more a genuine hydrogen bond; it is an electrostatic attraction of a positive charge on the acidic hydrogen and a negative charge on the organic fluorine or the organic oxygen. ${ }^{15}$

The electron-pair acceptability of a solvent is a measure of the ability to donate hydrogen bonds or to solvate anions. The electronpair acceptability of a hydrogen atom (CF-H) that is attached to a carbon atom to which a fluorine atom is also bonded in FEC can be higher than that in PC. Indeed, the acceptor number $(A N)$ of FEC $(A N \approx 31.2)$ was considerably higher than that of PC $(D N=$ 18.3). ${ }^{16-18}$

\subsection{Transport properties of electrolytic solutions}

Viscosity is regarded as internal friction based on intermolecular forces and affects ionic conductivity of the electrolytic solution. Figure 2(a) shows the temperature dependence of viscosities $(\eta)$ of electrolytic solutions in FEC and PC. Included in this figure for comparison are data for FEC and PC solvents. The viscosities of the solvents and the electrolytic solutions decreased rapidly with an increase in temperature. The high translational kinetic energy allows intermolecular attractions to be overcome more easily. The solution
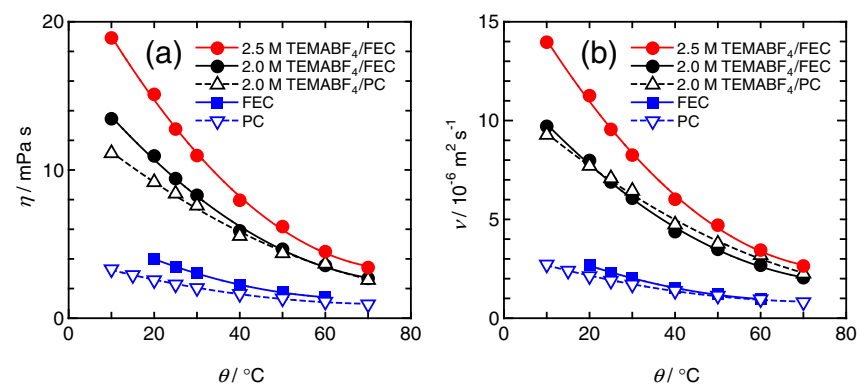

Figure 2. (Color online) (a) Viscosities $(\eta)$ and (b) kinematic viscosities $(v)$ of electrolytic solutions in FEC and $\mathrm{PC}$ as a function of temperature $(\theta)$ from 10 to $70^{\circ} \mathrm{C}$. The molar concentrations of $\mathrm{TEMABF}_{4}$ in $\mathrm{FEC}$ were set to 2.0 and $2.5 \mathrm{M}$ at $25^{\circ} \mathrm{C}$; and that of $\mathrm{TEMABF}_{4}$ in $\mathrm{PC}$ was set to $2.0 \mathrm{M}$ at $25^{\circ} \mathrm{C}$. Included in this figure for comparison are data for $\mathrm{FEC}$ and $\mathrm{PC}$ solvents.
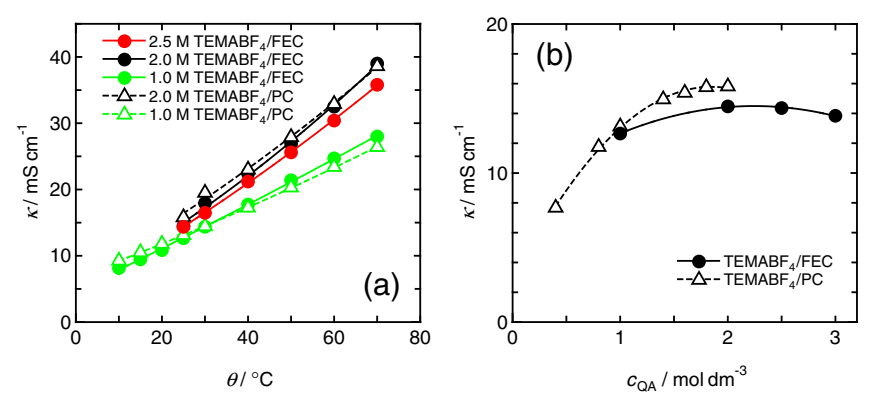

Figure 3. (Color online) (a) Ionic conductivities $(\kappa)$ of electrolytic solutions in FEC and PC as a function of temperature $(\theta)$ from -5 to $70^{\circ} \mathrm{C}$. The molar concentrations of $\mathrm{TEMABF}_{4}$ in FEC were set to $1.0,2.0$, and $2.5 \mathrm{M}$ at $25^{\circ} \mathrm{C}$; and those of $\mathrm{TEMABF}_{4}$ in $\mathrm{PC}$ were set to 1.0 and $2.0 \mathrm{M}$ at $25^{\circ} \mathrm{C}$. (b) Ionic conductivities of electrolytic solutions in FEC and $\mathrm{PC}$ at $25^{\circ} \mathrm{C}$ as a function of the molar concentration of $\mathrm{TEMABF}_{4}\left(c_{\mathrm{QA}}\right)$.

became the more viscous the denser it was. The viscosities of the solvents and electrolytic solutions decreased in approximately the following descending order: $2.5 \mathrm{M} \mathrm{TEMABF} / \mathrm{FEC}>2.0 \mathrm{M}$ $\mathrm{TEMABF}_{4} / \mathrm{FEC}>2.0 \mathrm{M} \mathrm{TEMABF} 4 / \mathrm{PC}>\mathrm{FEC}>\mathrm{PC}$. The viscosity of $2.0 \mathrm{M} \mathrm{TEMABF} 4$ solution in FEC was slightly higher than that of the counterpart in $\mathrm{PC}$ at room temperature. Kinematic viscosity $(v)$ is defined as the ratio of viscosity to mass density $(d)$ of a fluid: $v=\eta / d$. Since both the viscosity and the mass density are correlated with the molar masses of the electrolyte and the solvent, the effect of the molar mass on the kinematic viscosity can be small. Although the difference in the kinematic viscosities of FEC and PC solvents was smaller than that in the viscosities, the kinematic viscosity of the FEC solvent was slightly higher than that of the PC solvent. Interestingly, the kinematic viscosity of $2.0 \mathrm{M} \mathrm{TEMABF}_{4}$ solution in FEC was slightly lower than that of the counterpart in PC above room temperature, as shown in Fig. 2(b). The slight decrease in the kinematic viscosity of the FEC solution suggests that solvation of triethylmethylammonium ion $\left(\mathrm{TEMA}^{+}\right)$and tetrafluoroborate ion $\left(\mathrm{BF}_{4}^{-}\right)$in $\mathrm{FEC}$ is different from that in $\mathrm{PC}$.

\subsection{Ionic conductivities of electrolytic solutions}

The use of FEC as an alternative single solvent increased the solubility of $\mathrm{TEMABF}_{4}$. The solubility of TEMABF 4 in FEC was $3.0 \mathrm{M}$ or more at $25^{\circ} \mathrm{C}$, as shown in Fig. 3(b). In contrast, the solubility of $\mathrm{TEMABF}_{4}$ in $\mathrm{PC}$ is $2.2-2.3 \mathrm{M}$ at $25^{\circ} \mathrm{C}^{3,4}$

Conductivity of a solution is a dominant factor governing the internal resistance and rate performance of EDLCs. ${ }^{1,3}$ Figure 3 compares (a) the temperature $(\theta)$ and (b) concentration $\left(c_{\mathrm{QA}}\right)$ dependence of ionic conductivities $(\kappa)$ of electrolytic solutions in 

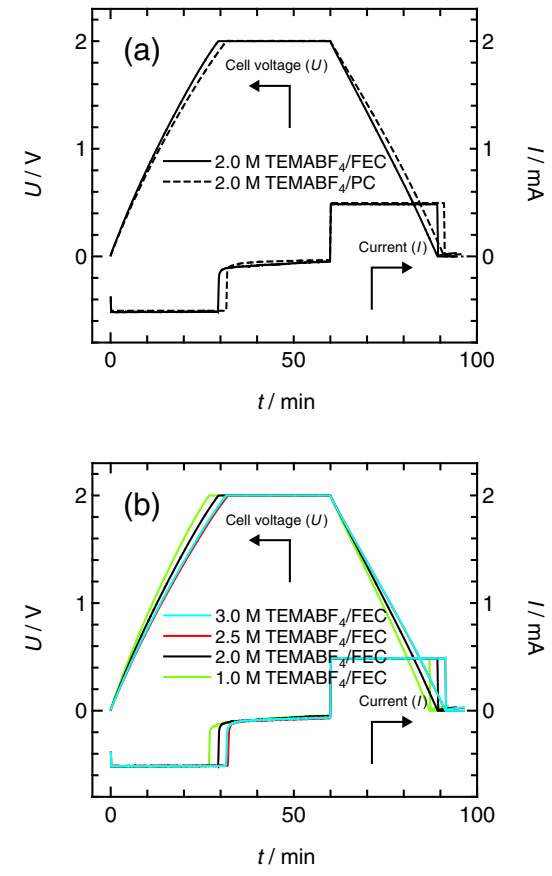

Figure 4. (Color online) Charge and discharge characteristics of 2025-type coin cells at $25^{\circ} \mathrm{C}$. Electrolytic solutions: (a) $2.0 \mathrm{M}$ $\mathrm{TEMABF}_{4}$ solutions in FEC and PC; and (b) 1.0, 2.0, 2.5, and $3.0 \mathrm{M}$ $\mathrm{TEMABF}_{4}$ solutions in FEC. The coin cells were charged from 0 to $2.0 \mathrm{~V}$ in a constant-current $(\mathrm{CC})\left(-0.5 \mathrm{~mA}\left(-60 \mathrm{~mA} \mathrm{~g}^{-1}\right)\right)$ mode and further charged to keep the constant voltage $(\mathrm{CV})$. Total charging time was set to $60 \mathrm{~min}$. The coin cells were then discharged to $0 \mathrm{~V}$ at $+0.5 \mathrm{~mA}$

FEC and PC. The conductivities of the electrolytic solutions increased with an increase in temperature. This is because the viscosities decreased rapidly with increasing temperature, as shown in Fig. 2(a). The ionic conductivities of the FEC solutions were slightly lower than those of the PC counterparts at the same concentrations of $\mathrm{TEMABF}_{4}$ at $25^{\circ} \mathrm{C}$. The maximal ionic conductivity was observed at about $2.0 \mathrm{M}$ in FEC. The conductivity is affected by the ionic mobility, the charge numbers of the ions, the concentration of the electrolyte, the degree of ionic dissociation of the electrolyte, etc. The ionic mobility is related to the viscosity of the electrolytic solution. The degree of ionic dissociation of the electrolyte is set by the balance of the permittivity, Lewis basicity, and Lewis acidity of the medium, depending on the concentration of the electrolyte.

The electron-pair donability of a solvent is a measure of the strength of the solvation of cations. A fluorine group is a strong electron-withdrawing substituent. The introduction of the fluorine group into ethylene carbonate (EC) can decrease the electron-pair donability of oxygen atoms of the OCOO moiety. The donor number $(D N)$ of FEC $(D N \approx 9.1)$ was much lower than that of PC $(D N=$ $15.1) .{ }^{16-18}$ In contrast, the acceptor number of $\operatorname{FEC}(A N \approx 31.2)$ was considerably higher than that of PC $(D N=18.3)$, as described in the previous section. The ionic dissociation of $\mathrm{TEMABF}_{4}$ at the high concentrations may be the result of a balance of solvation of $\mathrm{TEMA}^{+}$and $\mathrm{BF}_{4}^{-}$.

\subsection{Performance of EDLCs}

We evaluated integral full-cell capacitances per unit mass of activated carbon from discharge curves of 2025-type coin cells. Figure 4 shows the charge and discharge curves of the coin cells at $0.5 \mathrm{~mA}\left(60 \mathrm{~mA} \mathrm{~g}^{-1}\right)$ at $25^{\circ} \mathrm{C}$. The reciprocals of the slopes of the charge and discharge curves reflect the integral full-cell capacitances. The use of TEMABF 4 at the high concentrations in FEC slightly increased the gravimetric capacitance in the discharge: $28.1 \mathrm{~F} \mathrm{~g}^{-1}$ for $3.0 \mathrm{M} \mathrm{TEMABF} 4 / \mathrm{FEC}, 28.1 \mathrm{Fg}^{-1}$ for $2.5 \mathrm{M} \mathrm{TEMABF} 4 / \mathrm{FEC}$, $27.1 \mathrm{Fg}^{-1}$ for $2.0 \mathrm{M} \mathrm{TEMABF} 4 / \mathrm{FEC}$, and $27.5 \mathrm{Fg}^{-1}$ for $2.0 \mathrm{M}$ $\mathrm{TEMABF}_{4} / \mathrm{PC}$. A very small distance between activated carbon electrodes in the coin cell can compensate for the lower ionic mobility of TEMABF 4 in the bulk of the FEC solution. Furthermore, FEC may weaken solvation of electrolyte ions, and the electrolyte ions can closely approach the electrode in a compact double layer.

\section{Conclusion}

We have investigated the effect of the high concentrations of $\mathrm{TEMABF}_{4}$ on the bulk properties of the electrolytic solution and on the performance of EDLCs. The solubility of $\mathrm{TEMABF}_{4}$ in FEC was $3.0 \mathrm{M}$ or more at $25^{\circ} \mathrm{C}$. As the molar concentration of $\mathrm{TEMABF}_{4}$ increased, the molar concentrations of the solvents gradually decreased. The molar concentration of FEC in $2.5 \mathrm{M}$ $\mathrm{TEMABF}_{4}$ solution was higher than that of PC in $2.0 \mathrm{M} \mathrm{TEMABF}_{4}$ solution. The viscosity of $2.0 \mathrm{M} \mathrm{TEMABF} 4$ solution in FEC was slightly higher than that of the counterpart in $\mathrm{PC}$ at room temperature. On the other hand, the kinematic viscosity of $2.0 \mathrm{M} \mathrm{TEMABF}_{4}$ solution in FEC was slightly lower than that of the counterpart in $\mathrm{PC}$ above room temperature. The donor number of FEC $(D N \approx 9.1)$ was much lower than that of PC $(D N=15.1)$. In contrast, the acceptor number of FEC $(A N \approx 31.2)$ was considerably higher than that of PC $(D N=18.3)$. The ionic conductivities of the FEC solutions were slightly lower than those of the PC counterparts at the same concentrations of $\mathrm{TEMABF}_{4}$ at $25^{\circ} \mathrm{C}$. Nevertheless, the use of $\mathrm{TEMABF}_{4}$ at the high concentrations in FEC slightly increased the gravimetric capacitance of coin cells. It is very intriguing to investigate gravimetric capacitances of positive and negative electrodes separately from each other with three-electrode test cells.

\section{References}

1. B. E. Conway, Electrochemical Supercapacitors, Kluwer Academic/Plenum Publishers, New York (1999).

2. N. Nanbu, K. Suzuki, N. Yagi, M. Sugahara, M. Takehara, M. Ue, and Y. Sasaki, Electrochemistry, 75, 607 (2007).

3. M. Ue, Capacitor Binran (Eds. Y. Matsuda, T. Osaka, and Y. Sato), Maruzen, Tokyo, p. 257 (2009). [in Japanese]

4. K. Chiba, T. Ueda, Y. Yamaguchi, Y. Oki, F. Saiki, and K. Naoi, J. Electrochem. Soc., 158, A1320 (2011).

5. K. Hagiyama, K. Suzuki, M. Ohtake, M. Shimada, N. Nanbu, M. Takehara, M. Ue, and Y. Sasaki, Chem. Lett., 37, 210 (2008).

6. J. A. Riddick, W. B. Bunger, and T. K. Sakano, Organic Solvents: physical properties and methods of purification, 4th ed., Wiley-Interscience, New York, p. 435 (1986).

7. R. McMillan, H. Slegr, Z. X. Shu, and W. Wang, J. Power Sources, 81-82, 20 (1999).

8. R. Mogi, M. Inaba, S.-K. Jeong, Y. Iriyama, T. Abe, and Z. Ogumi, J. Electrochem. Soc., 149, A1578 (2002).

9. M. Kobayashi, T. Inoguchi, T. Iida, T. Tanioka, H. Kumase, and Y. Fukai, J. Fluorine Chem., 120, 105 (2003).

10. N. Nanbu, T. Ebina, H. Uno, Y. Miyazaki, and Y. Sasaki, Electrochem. Solid-State Lett., 9, A482 (2006); Erratum, 10, S3 (2007).

11. N. Nanbu, T. Ebina, H. Uno, S. Ishizawa, and Y. Sasaki, Electrochim. Acta, 52, $1763(2006)$

12. N. Nanbu, M. Takehara, S. Watanabe, M. Ue, and Y. Sasaki, Bull. Chem. Soc. Jpn., 80, 1302 (2007)

13. N. Nanbu, S. Watanabe, M. Takehara, M. Ue, and Y. Sasaki, J. Electroanal. Chem., 625, 7 (2009).

14. M. Handa, M. Kataoka, M. Wakaumi, and Y. Sasaki, Bull. Chem. Soc. Jpn., 70, 315 (1997).

15. K. Uneyama, Organofluorine Chemistry, Blackwell Publishing, Ltd., Oxford, p. 173 (2006).

16. Y. Marcus, The Properties of Solvents, John Wiley \& Sons, Chichester, p. 149 (1998).

17. W. R. Fawcett, Liquid, Solutions, and Interfaces, Oxford University Press, Inc., New York, p. 192 (2004).

18. K. Izutsu, Electrochemistry in Nonaqueous Solutioins, Second, Revised and Enlarged Edition, Wiley-VCH, Weinheim, p. 16 (2009). 